\title{
Displacements Schemes for Obtaining the Frequency Dependence on the Cottonseeds Moisture
}

\author{
Nasirov Tulkun Zakirovich, Ismatullayev Patxulla Raxmatovich, Jabborov Hamdam \\ Shaymardonovich, Eraliyeva Yulduzxon Mumtoz qizi
}

\begin{abstract}
The mathematic model of the high frequency moisture meter for cottonseeds has been constructed, in which the studying material as a complex dielectric installing in an electric field is represented. The displacement scheme which includes capacity between electrodes and also capacities and resistors corresponding to different polarization types has been presented. 4 variants of displacement schemes which describe approximately the dependence of angle tangency of dielectric losses on the electromagnet field frequency using in the measuring device have been considered. It has been shown that the simplest two element $R-C$ scheme connected parallel corresponds to the closest real description of measuring object in frequencies range from $10^{5}$ up to $10^{8}$ Hertz.
\end{abstract}

Keywords: displacement scheme, moisture, capacity, cottonseeds

\section{INTRODUCTION}

It is known that high frequency measurement method of the moisture is based to dependence of dielectric parameters and connected with them electric quantities on the materials moisture. For measuring moisture most often the middle and long wave ranges of high frequencies (from 0.1 up to 50 Mega Hertz) are being used. In this range the first capacity transformers of dielcometric moisture meters we can consider as a system with concentrated parameters.

In order to increase the accuracy of digital moisture meters used for measuring of different materials having high electric conductivity in paper [1] to use the two parameters controlling method based on the measuring and comparing with allowing values of the amplitude and phase of output

Revised Manuscript Received on May 15, 2020.

* Correspondence Author

Nasirov Tulkun Zakirovich*, Department of Electronics and Automatics of Tashkent State Technical University, Tashkent, Uzbekistan. E-mail: tulkunnasirov@yandex.ru

Ismatullayev Patxulla Raxmatovich, Department of Electronics and Automatics of Tashkent State Technical University, Tashkent, Uzbekistan. E-mail: tulkunnasirov@yandex.ru

Jabborov Hamdam Shaymardonovich, Department of Electronics and Automatics of Tashkent State Technical University, Tashkent, Uzbekistan. E-mail: tulkunnasirov@yandex.ru

Eraliyeva Yulduzxon Mumtoz qizi, Department of Electronics and Automatics Of Tashkent State Technical University, Tashkent, Uzbekistan. E-mail: tulkunnasirov@yandex.ru

(c) The Authors. Published by Blue Eyes Intelligence Engineering and Sciences Publication (BEIESP). This is an open access article under the CC BY-NC-ND license (http://creativecommons.org/licenses/by-nc-nd/4.0/) signal of measuring transformer with capacity sensor exciting high frequency signal had been proposed. Pekler V.V. presented [2] characteristics to modern industry heat gravimetrical, dielcometrical, neutron and microwave moisture meters. In particularly, the dielcometrical moisture meters the dielcometrical (capacity) principle of moisture measurement are realizing.

By interaction with analyzing material the moisture meter sensor produces a signal which proportional to substance dielcometrical permeability and transforming lately to the moisture value. Such moisture meters with average values of measuring accuracy of materials moisture in field conditions are being characterized.

In order to increase veracity of moisture control in high active conductivity conditions of the controlling material Lisichkin V.G. had proposed [3] to use two parametrical method of resonance dielcometrical measurements. The device scheme which allows realizing this method and decreasing considerably the measures errors and also lowering the consumer power had been developed and experimentally tested.

The questions on projecting the high frequencies method by Kalandarov P.I. had been considered there on its base devices variants of moisture control of capacity measuring transformers had been proposed [4]. Because of instability of constructive characteristics of first measuring transformer leads to essential errors there the method of engineering calculation of geometrical sizes and their working capacity had been developed.

And in paper [5] the calculation method of capacity transformers for moisture measuring on base of registration of dielectric permeability signal of considering materials has been proposed. There the rational choice of capacity transformers electrodes sizes for controlling materials had been realized. Used in this paper approach allowed synthesize the electric capacity model of first measuring transformer and its apparatus realization that in combine provides the acceptable approximation of real frequency moisture characteristics in the high frequencies ranges.

In manual [6] the main instructions for obtaining measurement information on the technological processes parameters had been considered there the measuring moisture methods and principles, devices and schemes elements also had been described.

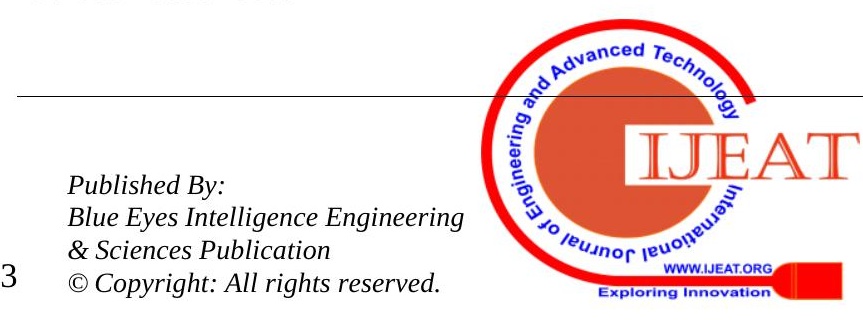




\section{Displacements Schemes for Obtaining the Frequency Dependence on the Cottonseeds Moisture}

It should be noted that there is lately devices review on using for quantitative definition of water composition in the oil and oil products [7]. Bibik G.A. could increased the measuring accuracy, simplified device and its exploitation, cut the measuring time, expand the device functional possibilities on measuring of moisture of dry materials [8].

In paper [9] the theoretical bases of dielcometric method for measuring of moisture had been presented.

It is known that the dielectric properties any humid material by following characteristics is described: complex dielectric permeability [3]

$$
\varepsilon^{*}=\varepsilon^{\mathrm{Re}}+i \varepsilon^{\mathrm{Im}},
$$

tangency angle of dielectric losses

$$
\operatorname{tg} \delta=\frac{\varepsilon^{\mathrm{Im}}}{\varepsilon^{\mathrm{Re}}}
$$

and complex conductivity

$$
\sigma^{*}=\sigma^{\mathrm{Re}}+i \sigma^{\mathrm{Im}}
$$

here $\varepsilon^{\mathrm{Re}}$ and $\varepsilon^{\mathrm{Im}}$ are the real and imaginary compositions of dielectric permeability, $\sigma^{\mathrm{Re}}$ and $\sigma^{\mathrm{Im}}$ are the real and imaginary compositions of conductivity.

In the present paper we propose the mathematical model of high frequency moisture meter which allows to obtain accuracy mathematical description in sufficiently level its transformation function and affecting the main quantities function.

\section{CONSTRUCTION OF MATHEMATICAL MODEL FOR HIGH FREQUENCY MOISTURE METER}

It is known that practically any device on measuring moisture of dry materials as generalized structure scheme (Fig. 1) based on any electro physical, in particularly, dielcometric method of moisture meter consisting three consequently connected elements can be presented. Herewith element 1 corresponds to transformation of measuring quantity, that is moisture, $W$, to physical (in our case to electrical) one, "e", that is describes the dependence using in this method electrical properties of material on its moisture. And element 2 is the first measuring transformer (sensor) of moisture meter which transforms quantity, "e", to output signal, "x" (capacity, complex resistor or one of its compositions), easily for future processing. As to the last element, 3, it describes the measuring transformer (measuring device) in output that an analogical or digital signal, "y", is been obtained.

In order to describe the affecting function of non informatics parameters we must into account the interferences reacting to mentioned above elements, $1-3$. For example, to element 1 affect the temperature, density, chemical composition and other parameters measuring material influencing to its dielectric characteristics (the quantity, z); and to element 2 affect the material shape and mass, frequency of the electric current and et al. which influence to measuring device characteristics.

Description of element 1 that is moisture transformation to dielectric properties especially difficult for using to nature moisture-containing materials, in particularly, to the biological ones with plant origin such as cottonseeds and their recast products.
Such complicated many component and heterogeneous on structure materials such as cottonseeds to the heterogeneous systems class are relating and by description their electric properties we must take into account both methods of modern insulators physics and also heterogeneous solutions features [10].

In the alternative electric field the main process defining properties of the real insulator is polarization. In the cottonseeds almost all polarization types, that is electronic, ionic, dipole-relaxation, electrolytic, and structure are observed. And resulting polarization by sum of all having in concrete material polarization types is defined moreover in dependence on the material features the different types have a more or less proportion. For example, in cotton and cotton materials the dominated value in high frequencies range there are inertial polarization types, that is dipole-relaxation and structure ones.

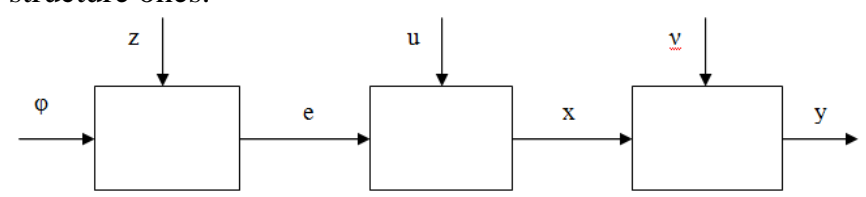

Fig. 1. Generalized structure of moisture meter scheme

In the most general form the complicated insulator in an electric field with equivalent scheme presented in Fig. 2 can be described. The scheme includes capacity between electrodes in vacuum, $\mathrm{C}_{0}$, and capacities sum $\mathrm{C}_{\mathrm{e}}, \mathrm{C}_{\mathrm{i}}, \mathrm{C}_{\mathrm{s}}, \mathrm{C}_{\mathrm{d}}$ and $\mathrm{C}_{\mathrm{ip}}$, corresponding to different polarization types. In the equivalent scheme there are also consequent resistors $R_{i}, R_{s}$, $R_{d}$ and $R_{i p}$ which take into account the energy losses because of polarization. Moreover in the scheme the active resistor $\mathrm{R}$ characterizing through current between electrodes is taken into account.

From this equivalent scheme flowed out two important features of moisture transformation to output signal of dielcometric high frequencies first transformer.

The first of them dealing with that output signal always has the complex character that is the total resistor of first measuring transformer with a material is the complex quantity. Moreover, the reactive (capacitor) composition of this resistor deals with the dielectric permeability and the active one with dielectric losses and conductivity ones.

The second feature appears with the dielectric parameters of measuring material depend on frequency of electromagnetic field using in device for measuring materials moisture. This circumstance with dependence of different polarization types on frequency can be explained. For example, the structure (interlayer) polarization influences basically on low frequencies. However, such polarization in case of presence of micro heterogeneities in cotton components in more high frequencies can be appeared too. It should be noted that the polarization degree increasing entails increasing of its dielectric permeability too. And with frequency increasing the decreasing of polarization sum because of inertia and other effects can be expected. To this effect corresponds decreasing of $\varepsilon^{\mathrm{Re}}$ value.
Published By:

Blue Eyes Intelligence Engineering

\& Sciences Publication

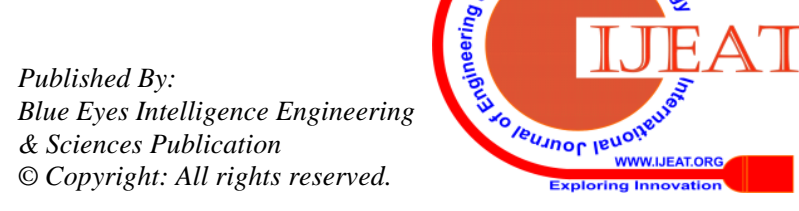


Influence of frequency to dielectric characteristics in the heterogeneous moisture-containing systems by several factors is aggravated. In other words, the frequency characteristics of dielectric properties of heterogeneous mixture as well as temperature characteristics differ considerably from ones separate components.

Because of presence of interaction of dispersion media with dispersion phase dispersion range is being expending and the relaxation phenomenon only one concrete frequency but in the wide frequencies spectra range may be not taken place even sometimes several maximums of parameter $\varepsilon^{\operatorname{Im}}$ is observing.

Affect of double polarized layer of particles on surface of the component system section leads to that heterogeneous mixture especially in low frequencies range can acquire the dielectric permeability exceeding than $\varepsilon^{*}$ any component, in particularly water too. The second factor on influencing conducting of particles or inclusions is the particles shape. Finally, in considering systems the shape and moisture connection type with dry substance have the essential value.

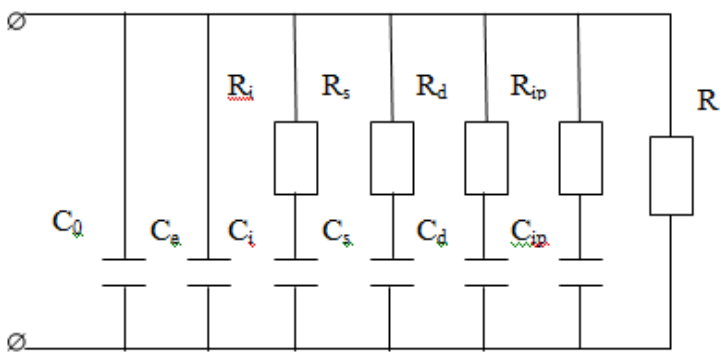

Fig. 2. The equivalent scheme of complicated insulator:

$C_{0}$ is the capacity in vacuum; $C_{e}$ is the electron

polarization capacity; $C_{i}$ is the ion polarization capacity; $\mathrm{C}_{\mathrm{s}}$ is the structure polarization capacity; $C_{d}$ is the dipole polarization capacity; $C_{i p}$ is the interlayer polarization capacity; $\mathbf{R}_{\mathrm{i}}, \mathbf{R}_{\mathrm{s}}, \mathbf{R}_{\mathrm{d}}$ and $\mathbf{R}_{\mathrm{ip}}$ are the corresponding active losses resistors in mentioned above types polarization; $R$ is the - resistor of the through current.

In paper [11] the different mechanisms provocative losses in the heterogeneous systems in the wide frequencies range had been summarized (Fig. 3). There two ranges which different essentially from each other can be distinguished. In the low frequencies range the losses due to several effects superposition separating ones too difficult. As to the super high frequencies range the picture is being simplified. The main losses type became relaxation polarization due to its slowly established types. This mechanism, in particularly, explains minimization of errors by measurement in super high frequencies related to the availability electrolytes (salts, acids) in water in comparison of the measurements by more lower frequencies, in particularly, in high frequencies range.

The cottonseeds representing a complex heterogeneous system differ by high degree of heterogeneity on structure. Polarization sum in cottonseeds has the essential wide, continuous practically time spectrum establishing of different polarization types. If we start even from the simplified model of the cottonseeds as the three phases system containing their moisture fiber and air then the dielectric properties of their components will different on the essential degree. Water as inclusion to non-conductive and non-relaxation media (dry core, sheath, fluff and air) can be considered. In this case the moisture forms both big (film in cottonseeds, fluff surface, liquid water in big pores) and as well small inclusions (moisture in cottonseeds small pores, in spaces between fibrils and mussels).

\section{EQUIVALENT SCHEMES IN INVESTIGATING THE DEPENDENCE OF ELECTRIC PARAMETERS ON THE MEASURING DEVICE FREQUENCY}

By increasing moisture one not in type of separating disparate inclusions but in solid films shape, bridges and et al is distributing. This determines a wide, continuous practically equivalent scheme. We chose 4 variants of equivalent schemes (Fig. 4) corresponding approximately to the considered in Fig. 3 characteristics of parameter $\operatorname{tg} \delta(f)$.

If we start from the exclusion method then became immediately apparent that scheme (b) of Fig. 4 must be excluded from consideration thus its characteristics tg $\delta(f)$ has extremum in the same time real characteristics of cottonseeds and cotton oil products has not an extremum (Fig.

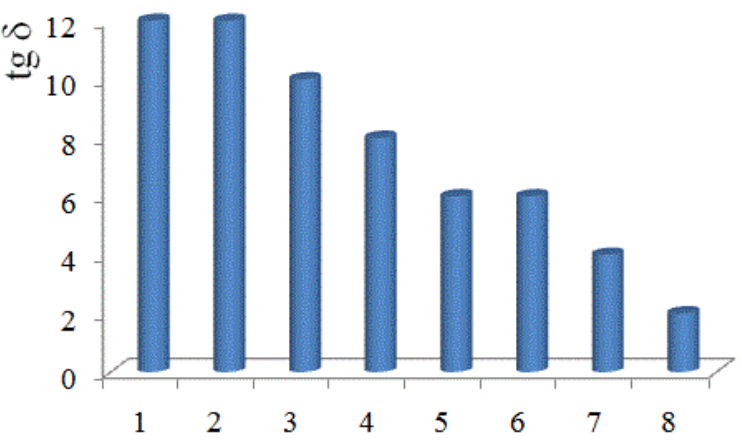

Fig. 3. Dielectric losses in the containing water heterogeneous systems. Here first column corresponds to ice relaxation; the second - to water relaxation; the third - to Maxwell-Wagner losses; the fourth - to conductivity; the fifth - to crystal hydrate water; the sixth - connected water; the seventh - to surface conductivity and the eighth - to charged doubled layer.

Consequently, for comparing we shell consider other 3 equivalent schemes (a), (c) and (d) of Fig 4. Here scheme (a) corresponds to main two element scheme and c) and d) schemes have characteristics $\operatorname{tg} \delta(f)$ which most closest to characteristics of scheme a).

In order to compare more detail of remaining three equivalent schemes we must conduct analysis of characteristics for each of them on minimum of average quadratic deviations

$$
\Delta=\sum_{i=1}^{n} g_{i}^{2}\left[y_{i}-\operatorname{tg} \delta\left(f_{i}, a, b, c\right)\right],
$$

where $g_{i}$ is the shared function, $y_{i}$ is the characteristics ordinates, $\operatorname{tg} \delta_{i}(f)$ angle tangency of losses for approximation scheme, $a, b, c$ are the coefficients.

Approximation coefficients $a, b$ and $c$ from minimization of errors conditions are defined

Published By:

Plue Eyes Intelligence Engineering

\& Sciences Publication

(C) Copyright: All rights reserved. 
Displacements Schemes for Obtaining the Frequency Dependence on the Cottonseeds Moisture

$$
\frac{\partial \Delta}{\partial a}=0 ; \frac{\partial \Delta}{\partial b}=0 ; \frac{\partial \Delta}{\partial c}=0 .
$$

It is known that for scheme a is fairly the expression (Fig. 5)

$$
\operatorname{tg} \delta=\frac{1}{\omega \tau}
$$

where $\tau=\mathrm{RC}$.

By equal shares sum (1) represents as

$$
\Delta=\sum_{i=1}^{n}\left(y_{i}-\frac{1}{\omega_{i} \tau}\right)^{2}
$$

here the minimization factor role can play time constant $\tau$. Its required value we find from equation

$$
\frac{\partial \Delta}{\partial \tau}=0
$$

and define with expression

$$
\tau=\frac{\sum_{i=1}^{n} \frac{1}{\omega_{i}^{2}}}{\sum_{i=1}^{n} \frac{y_{i}}{\omega_{i}}} .
$$

Now we shell consider (c) scheme of Fig. 4. For one dependence $\operatorname{tg} \delta(\omega)$ is written

$$
\operatorname{tg} \delta=\frac{\omega^{2} C_{1} C_{2} R_{1} R_{2}\left(R_{1}+R_{2}\right)+\omega C_{1} R_{1}}{C_{2}^{2} C_{1}\left[C_{2}\left(R_{1}+R_{2}\right)^{2}+C_{1} R_{1}^{2}\right]+1}
$$

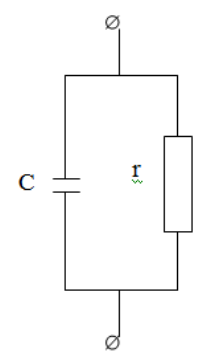

(a)

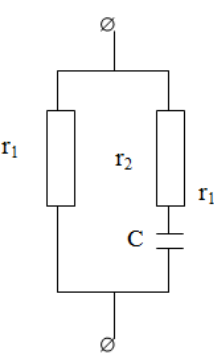

(b)

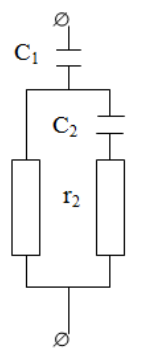

(c)

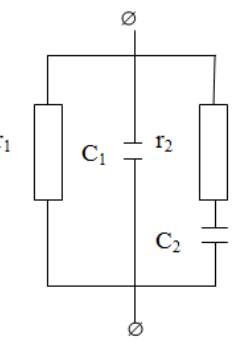

(d)
Fig. 4. Typing equivalent schemes (R-C-schemes)

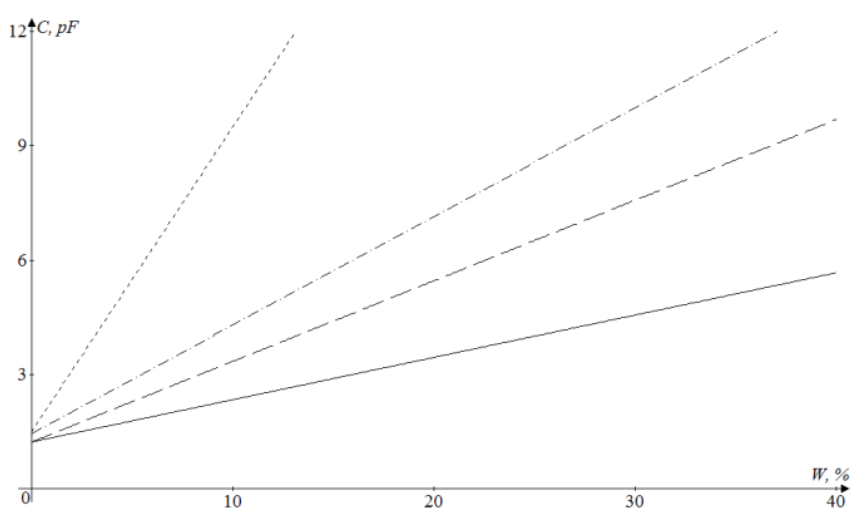

Fig. 5. Dependence of electric capacity on moisture, $W$, by frequencies 28.4 Mega Hertz (solid line), 4.6 Mega Hertz (long dashed line), 1 Mega Hertz (dotted-dashed line) and 0.3 Mega Hertz (short dashed line).

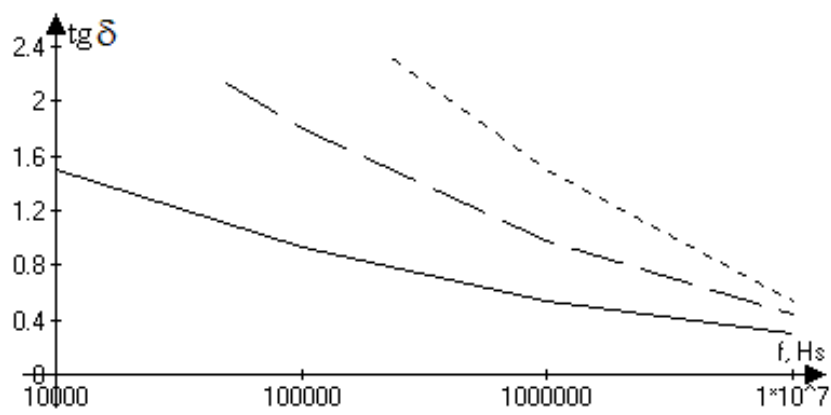

Fig. 6. Dependence of $\operatorname{tg} \delta$ on frequency by moisture values $10 \%$ (solid line), $20 \%$ (long dashed line) and $30 \%$ (short dashed line).

We introduce the following designations

$$
\begin{gathered}
a=(2 \pi)^{3} C_{1} C_{2}^{2} R_{1} R_{2}\left(R_{1}+R_{2}\right) ; \\
b=2 \pi C_{1} R_{1} ; \\
c=(2 \pi)^{2} C_{2}\left[C_{2}\left(R_{1}+R_{2}\right)^{2}+C_{1} R_{1}^{2}\right] .
\end{gathered}
$$

Then representation (6) has form

$$
\operatorname{tg} \delta=\frac{a f_{i}^{3}+b f_{i}}{c f_{i}^{2}}
$$

and for equal shares sum (4) will take the form

$$
\Delta=\sum_{i=1}^{n}\left(y_{i}-\frac{a f_{i}^{3}+b f_{i}}{c f_{i}^{2}+1}\right)^{2} .
$$

After minimization of average quadratic errors on parameters $a, b$ and $c$ according to condition (2) we shell obtain following equations system

$$
\begin{gathered}
\sum_{i=1}^{n}\left(y_{i}-\frac{a f_{i}^{3}+b f_{i}}{c f_{i}^{2}+1}\right)\left(\frac{-f_{i}^{3}}{c f_{i}^{2}+1}\right)=0 ; \\
\sum_{i=1}^{n}\left(y_{i}-\frac{a f_{i}^{3}+b f_{i}}{c f_{i}^{2}+1}\right)\left(\frac{-f_{i}}{c f_{i}^{2}+1}\right)=0 ; \\
\sum_{i=1}^{n}\left(y_{i}-\frac{a f_{i}^{3}+b f_{i}}{c f_{i}^{2}+1}\right)\left(\frac{a f_{i}^{3}+b f_{i}}{c f_{i}^{2}+1}\right)^{2} f_{i}^{2}=0 .
\end{gathered}
$$

For scheme (d) of Fig. 4 parameter $\operatorname{tg} \delta(\omega)$ with following expression is described

$$
\operatorname{tg} \delta=\frac{1+\omega^{2} C_{1} R_{1}\left(R_{1}+R_{2}\right)}{\omega^{3} R_{1}^{2} R_{2} C_{1}^{2} C_{2}+\omega R_{2}\left(C_{1}+C_{2}\right)} .
$$

If we include designations:

$$
\begin{aligned}
& a=(2 \pi)^{3} R_{1} R_{2} C_{1}^{2} C_{2} ; \\
& b=2 \pi R_{2}\left(C_{1}+C_{2}\right) ; \\
& c=(2 \pi)^{2} 2 C_{1}^{2} R_{1}\left(R_{1}+R_{2}\right),
\end{aligned}
$$

then expression (10) takes form

$$
\operatorname{tg} \delta=\frac{c f_{i}^{2}}{a f_{i}^{3}+b f_{i}} .
$$

After substituting expression (11) to representation (1) we shell obtain

Published By:

Blue Eyes Intelligence Engineering

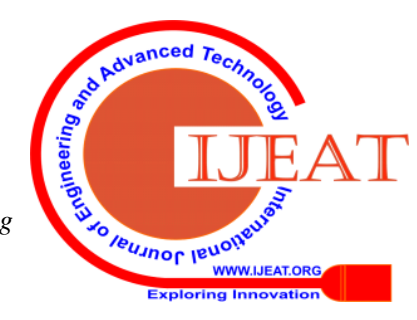




$$
\Delta=\sum_{i=1}^{n}\left(y_{i}-\frac{c f_{i}^{2}+1}{a f_{i}^{3}+b f_{i}}\right) .
$$

By exercising minimization of average quadratic errors on parameters $a, b$ and $c$ according conditions (2) we shell obtain following equations system

$$
\begin{aligned}
& \sum_{i=1}^{n} \frac{\left(c f_{i}^{2}+1\right) f_{i}}{\left(a f_{i}^{2}+b\right)^{2}}=\sum_{i=1}^{n} y_{i} \frac{\left(c f_{i}^{2}+1\right) f_{i}^{2}}{a f_{i}^{2}+b} ; \\
& \sum_{i=1}^{n} \frac{c f_{i}^{2}+1}{\left(a f_{i}^{2}+b\right)^{2}}=\sum_{i=1}^{n} y_{i} \frac{c f_{i}^{2}+1}{a f_{i}^{2}+b} \\
& \sum_{i=1}^{n} \frac{c f_{i}^{2}+1}{\left(a f_{i}^{2}+b\right)^{2}}=\sum_{i=1}^{n} \frac{f_{i}}{a f_{i}^{2}+b} .
\end{aligned}
$$

\section{CALCULATION RESULTS}

Values of parameters $a, b$ and $c$ in expressions (7)-(12) we calculate using the least descent method. Based on obtained values of these coefficients and expressions written above the values of approximation functions $\operatorname{tg} \delta$ have been calculated results of which by cottonseeds moisture values $10 \%, 20 \%$ and 30\% have been represented in Fig. 6 .

It is seen from the Figure that in all values of materials moisture the tangency angle losses values are decreased monotonic practically by logarithmic law. It should be noted also that when the moisture increases then $\operatorname{tg} \delta$ values will be increased too and dependence curve of $\operatorname{tg} \delta$ on moisture value will be getting more sharper.

As example in this Figure for cottonseeds with moisture $W=20 \%$ the calculation results of approximation characteristics of tg $\delta$ of equivalent schemes (a), (c) and (d) with main (experimental) characteristics are compared. This comparison shows persuasively that the simplest parallel two elements R-C equivalent scheme (a) of Fig. 4 is the closest to real measuring object in all investigating ranges of high frequencies from $10^{5}$ up to $10^{8}$ Hertz.

\section{CONCLUSION}

Thus, based on the investigation results for dependence of cottonseeds moisture on the frequency via equivalent schemes we can conclude the following highlights.

The first, the mathematical model of high frequency moisture meter for cottonseeds has been constructed in which the measuring material as complex insulator in the electric field has been represented.

The second, the equivalent scheme including the capacity and resistor corresponding to different polarization types has been studied.

The third, four equivalent schemes describing approximately the dependence of tangency angle of dielectric losses on the electromagnetic field frequency used in the measuring device have been considered.

The fourth, it has been shown that the simplest R-C equivalent scheme corresponds to the closest real description of measuring object in ranges from $10^{5}$ up to $10^{8}$ Hertz.

The fifth, it has been revealed that the capacity of measuring device depends on the cottonseeds moisture practically linear and besides when frequency is decreasing the dependence sharper is getting.

\section{REFERENCES}

1. Ivanov B.R., Lisichkin V.G., Shvedov S.N. Two parametrical device for moisture control (in Russian) // Izvestiya OryolGTU. 2009. № 6/278(577). P. 84-88.

2. Pekler V.V. Moisture meter science of dry materials: the present status and developing prospects (in Russian) // Metodi otsenki sootvetstviya. 2009. № 9. P. 15-17.

3. Lisichkin V.G. two parametrical device for resonance control of moisture with low power consumption (in Russian) // Priborostroyeniye i biotexnicheskiye sxemi. 2011. № 1(285). P. 134-140.

4. Kalandarov P.I., Masharipov Sh.M., Iskandarov B.P., Xaitov B.M. On the projection of moisture capacity first measuring transformers (in Russian) // Matematicheskoye i programmnoye obespecheniye v promishlennoy i sotsial'noy sferax. 2013. № 1(3) P. 62-69.

5. Iskandarov B., Kalandarov P.I. High frequencies device for moisture control of margarine mass based on capacity transformers (in Russian) // Nauchnii jurnal «Aprobatsiya». 2013. № 6 (9). P. 8-13.

6. Borisov V.P., Beryozin M.A., Kuznetsov V.V., Borisov V.S. Basics of measurement of main technologic parameters of food production: tutorial (in Russian). Publishing house "Mordoviya-ekspo". Saransk. Russia. 2011. 234 p.

7. Shirokov I.B., Maronchuk I.I. Devices using for defining water composition in oil and oil products (review) (in Russian) // Energeticheskiye ustanovki i texnologii. 2018. V.4. № 1. P. 56-73.

8. Bibik G.A. Many channel device for measuring of loose materials moisture (in Russian). Patent. 2016. RU. 2653 091. C1.

9. Usmanova X.A., Turg'unbayev A. Theoretical basics of dielcometric moisture measuring method (in Russian) // Pribori. 2017. № 8. P. 34-40.

10. Kochetov N.A., Rogachyov A.S., Yemelyanov A.N., Illarionova Ye.V, Shkirov V.M. Microstructure of heterogeneous mixtures for gasless burning (in Russian) // Fizika goreniya i vzriva. 2004. V. 40. № 5 P. 74-81.

11. Polyakov I.Yu. and et al. Modern state of data transmission problem in heterogeneous communication systems (in Russian) // Dokladi TUSURa. 2017. V. 20. № 3. P. 177-180.

\section{AUTHORS PROFILE}

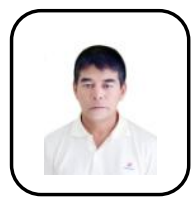

Nasirov Tulkun Zakirovich had obtained his high education in Physics faculty of Tashkent State University. In 1997 he had received Ph.D. degree in Institute of Nuclear Physics of Uzbekistan Academy of sciences. Today one is author of more than 60 scientific papers.

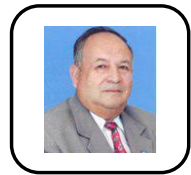

Ismatullayev Patxulla Raxmatovich had obtained his high education in Moscow chemical machinery institute. In 1988 he had received D.Sc. degree in Tashkent polytechnic institute. The last 5 years one had published more than 50 scientific papers.

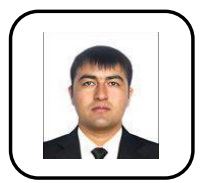

Jabborov Hamdam Shaymardonovich had obtained his high education in Tashkent State Technical University in 2011. Today one is author of about 50 scientific papers and working on conferment the Ph.D. degree.

Eraliyeva Yulduzxon Mumtoz qizi had obtained his high education in National University of Uzbekistan in 2018. Today she just starting its scientific investigations on conferment the Ph.D. degree.

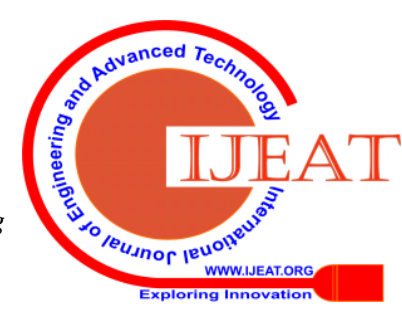

